\title{
A Systematic Review of Cost-Effectiveness Analyses for Hepatocellular Carcinoma Treatment
}

\author{
Sydney C. Yuen ${ }^{1} \cdot$ Adaeze Q. Amaefule ${ }^{1} \cdot$ Hannah H. Kim ${ }^{1} \cdot$ Breanna-Verissa Owoo ${ }^{1} \cdot$ Emily F. Gorman $^{2}$. \\ T. Joseph Mattingly II ${ }^{1}$ (I)
}

Accepted: 8 August 2021 / Published online: 24 August 2021

(c) The Author(s) 2021

\begin{abstract}
Background Hepatocellular carcinoma (HCC) is associated with significant financial burden for patients and payers. The objective of this study was to review economic models to identify, evaluate, and compare cost-effectiveness estimates for HCC treatments.

Methods A systematic search of the PubMed, Embase, and Cochrane Library databases to identify economic evaluations was performed and studies that modeled treatments for HCC reporting costs and cost effectiveness were included. Risk of bias was assessed qualitatively, considering costing approach, reported study perspective, and funding received. Intervention costs were adjusted to 2021 US dollars for comparison. For studies reporting quality-adjusted life-years (QALYs), we conducted analyses stratified by comparison type to assess cost effectiveness at the time of the analysis.

Results A total of 27 studies were included. Non-curative versus non-curative therapy comparisons were used in 20 (74.1\%) studies, curative versus curative comparisons were used in $5(18.5 \%)$ studies, and curative versus non-curative comparisons were used in $2(7.4 \%)$ studies. Therapy effectiveness was estimated using a QALY measure in $20(74.1 \%)$ studies, while 7 (25.9\%) studies only assessed life-years gained (LYG). A health sector perspective was used in $26(96.3 \%)$ of the evaluations, with only 1 study including costs beyond this perspective. Median intervention cost was $\$ 53,954$ (range \$4550-\$4,760,835), with a median incremental cost of $\$ 6546$ (range $-\$ 72,441$ to $\$ 1,279,764)$. In cost-utility analyses, $11(55 \%)$ studies found the intervention cost effective using a $\$ 100,000 / \mathrm{Q} A L Y$ threshold at the time of the study, with an incremental cost-effectiveness ratio (ICER) ranging from $-\$ 1,176,091$ to $\$ 1,152,440$ when inflated to 2021 US dollars.

Conclusion The majority of HCC treatments were found to be cost effective, but with significant variation and with few studies considering indirect costs. Standards for value assessment for HCC treatments may help improve consistency and comparability.
\end{abstract}

T. Joseph Mattingly II

jmattingly@rx.umaryland.edu

1 University of Maryland School of Pharmacy, 220 Arch

Street, 12th Floor, Baltimore, MD 21201, USA

2 Health Sciences and Human Services Library, University of Maryland, Baltimore, MD, USA 


\section{Key Points for Decision Makers}

In this systematic review of 27 unique economic evaluations, the median intervention cost was $\$ 53,954$, with a median incremental cost of $\$ 6546$. Of the 20 studies that included a quality-adjusted life-year (QALY) measure, 11 found the intervention to be cost effective using a $\$ 100,000 /$ QALY threshold at the time of the study but with significant variation and with few studies considering indirect costs.

Standards for future value assessment for hepatocellular carcinoma treatments could improve consistency and comparability, and patient engagement may ensure models reflect actual patient experiences.

\section{Introduction}

Hepatocellular carcinoma (HCC) has one of the highest mortality rates out of all cancers and is the fourth leading cause of cancer-related deaths worldwide [1,2]. In addition to mortality, patients with HCC may experience a variety of challenges impacting their overall quality of life (QoL), such as pain, lethargy, difficulty sleeping, alopecia, weight loss, etc. [3, 4]. The disease prognosis, treatment options, and patient experience further depends on the staging of the disease and the degree of liver dysfunction [4]. HCC also comes with a significant financial burden for both patients and payers [5, 6]. Many patients not eligible for transplant or resection may also forgo treatment due to high costs and limited benefits of other existing therapies [3].

Cost-effectiveness analysis (CEA) methods have been considered the 'gold standard' for developing objective estimates of the value of health interventions to inform decision making [7, 8]. While best practices and recommendations for CEAs exist, there are several researcher decisions, methodological approaches, and data sources that can introduce variability in the ultimate cost-effectiveness determination [9, 10]. For example, a 'societal perspective' that includes informal care (e.g., caregiver burden, time, travel) and non-healthcare costs (e.g., absenteeism, presenteeism) has traditionally been recommended [11] for CEAs, but most analyses focus on payer decisions that only incorporate formal healthcare costs (e.g., inpatient, outpatient, pharmacy, laboratory) [10]. Other researcher-level decisions can have a major influence on CEA results, such as population, comparator selection, time horizon, and health outcome measures. In order to accurately assess and compare the value of different innovations in the prevention, diagnosis, and treatment of HCC, these methodological considerations must be evaluated to determine the appropriateness of HCC-specific standards for economic evaluation. The objective of this systematic review was to identify, evaluate, and compare costeffectiveness estimates for different treatment approaches for HCC.

\section{Methods}

We performed a systematic search on 1 May 2020 to identify economic evaluations using the PubMed (PubMed.gov), Embase (Embase.com), and Cochrane Library (WileyOnline) databases.

\subsection{Search Strategy}

The search strategy for each database is provided in eAppendix 1. The review focused on answering the following questions.

1. What are the costs and incremental cost effectiveness of both curative and non-curative therapies for HCC?

2. What types of costs are frequently identified when comparing different HCC interventions?

3. What research methods are commonly used to evaluate cost effectiveness for HCC therapies?

\subsection{Selection Criteria}

The Preferred Reporting Items for Systematic Reviews and Meta-Analyses (PRISMA) and Consolidated Health Economic Evaluation Reporting Standards (CHEERS) guidelines were used for study eligibility criteria, quality assessment, and analysis of results $[12,13]$. The following inclusion criteria were used to screen articles.

1. Articles must be written in English.

2. Articles need to model interventions aimed at treating $\mathrm{HCC}$ in adults.

3. Articles must report economic information, including costs and cost effectiveness.

All abstracts were reviewed by at least two reviewers using Covidence [14] systematic review software to track discrepancies, with conflicts resolved by one of the authors (TJM). Full-text review was completed by at least two reviewers, with all papers reviewed by TJM. Inclusion disagreements were discussed until consensus was reached. 


\subsection{Data Extraction and Evidence Synthesis}

Data extraction included the following variables: article citation details (year, author, title), study type, study description, country, population description, intervention and comparators, and measure of effectiveness-quality-adjusted life-year (QALY) or life-years gained (LYG), description of costing methods, time horizon, discount rate, currency, description of sensitivity analysis, costs reported, and effectiveness reported. Using this extracted data, we identified the HCC stage based on the Barcelona Clinic Liver Cancer (BCLC) staging system [15], type of intervention (curative or non-curative), intervention costs adjusted to 2021 US dollars (US\$) using currency conversion and a 3\% discount rate for inflation [16], and whether the intervention would be considered cost-effective using a $\$ 100,000 /$ QALY threshold [17] at the time of the analysis. Curative therapies included liver transplant, resection, or radiofrequency ablation (RFA), while non-curative therapies included tyrosine kinase inhibitors (e.g., sorafenib, cabozantinib, lenvatinib), transarterial chemoembolization (TACE), transarterial radioembolization (TARE), stereotactic body radiotherapy (SBRT), and any palliative care or best supportive care $[18,19]$. Considering the potential for authors to report a study perspective that is not consistent with current recommendations, we used the costing methods described in the article to confirm the study perspective as either a health sector (direct costs only) or societal perspective (including any costs beyond direct medical costs in the health sector perspective such as productivity, time, consumption, etc.) [20].

For studies that report a QALY outcome, we conducted further exploratory analyses to compare cost effectiveness across this similar subset of CEAs commonly referred to as cost-utility analyses. In this comparison, the primary outcome of interest was the ICER (cost/QALY) calculated in US\$ at the time of the study. Since interpretation of positive and negative ICER values depends on the directionality of the numerator (intervention more or less costly) and denominator (intervention more or less effective), we plotted the incremental costs (y-axis) and incremental effects ( $\mathrm{x}$-axis) with the $\$ 100,000$ theoretical willingness-to-pay threshold for cost effectiveness, to illustrate which ICERs should be interpreted as cost effective (i.e., below the diagonal threshold) [21].

\subsection{Risk-of-Bias Assessment}

Risk of bias was assessed qualitatively, considering costing approach, reported study perspective, and type of funding received. Specifically, the authors considered how study perspective, intervention/comparator selection, length of time, and outcomes included might impact the study's ultimate cost-effectiveness conclusion.

\section{Results}

\subsection{Overview of Studies}

The economic literature search identified a total of 5816 records, with a total of 4304 remaining after duplicates were removed (Fig. 1). After abstract screening using the inclusion criteria, a total of 50 full-text articles were reviewed for inclusion, resulting in 27 unique studies included for extraction and synthesis (Table 1) [22-48].

\subsection{Modeling Methods}

Most economic evaluations were conducted for a single country $(22 / 27,81.5 \%)$, with $5(18.5 \%)$ studies evaluating the cost effectiveness in multiple countries. Models were limited to advanced HCC patients in 11 (40.7\%) studies, early HCC only in $6(22.2 \%)$ studies, and a combination of multiple HCC stages in the remaining 10 (37.0\%) studies. Non-curative versus non-curative (including supportive care) therapy comparisons were used in $20(74.1 \%)$ studies, curative versus curative comparisons were used in 5 $(18.5 \%)$ studies, and curative versus non-curative comparisons were used in 2 (7.4\%) studies. Therapy effectiveness was estimated using a QALY measure in $20(74.1 \%)$ studies, while 7 (25.9\%) studies only assessed LYG. A health sector perspective was used in $26(96.3 \%)$ of the evaluations, with only 1 study including costs beyond the health sector perspective [39]. In terms of funding received, 16 (59.3\%) studies either had no funding or did not disclose any funding sources, while 7 (25.9\%) received government-funded grants and $4(14.8 \%)$ were funded by industry or for-profit sources.

\subsection{Costs of Treatment}

A total of 25 (92.6\%) studies calculated the total costs of the intervention and comparator to assess the incremental costs, while 2 studies $[26,36]$ only reported the marginal costs for treatments assessed. The median intervention cost adjusted to 2021 US\$ was $\$ 53,954$ (range $\$ 4550-\$ 4,760,835$ ), with a median incremental cost of $\$ 6546$ (range $-\$ 72,441$ to $\$ 1,279,764)$.

\subsection{Cost-Utility Analyses}

Of the 20 studies that included a QALY measure, 11 (55\%) found the intervention to be cost effective using a $\$ 100,000 /$ QALY threshold at the time of the study, and $10(50 \%)$ found the intervention to be cost effective when inflating to 2021 US\$ (Table 2). When comparisons included two curative therapies $(n=4)$, median incremental costs were $\$ 48,249$ (range $-\$ 10,000$ to $\$ 163,006$ ), with median incremental 
Fig. 1 Review flow diagram according to the PRISMA statement. PRISMA Preferred Reporting Items for Systematic Reviews and Meta-Analyses, PICOS population, intervention, control and outcomes

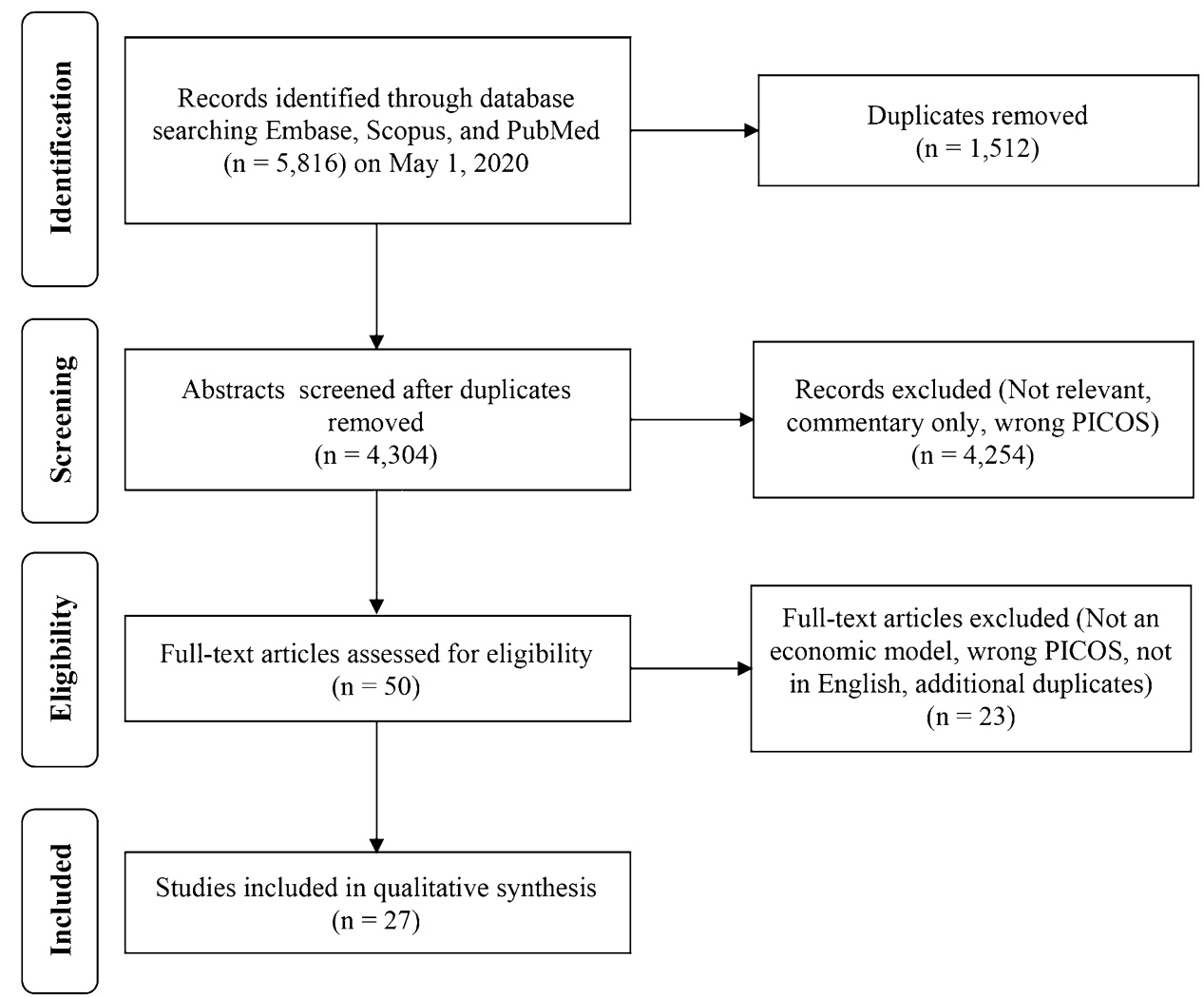

effects of 1.2 QALYs gained (range 0.3-2.4). When comparisons included two non-curative therapies $(n=16)$, median incremental costs were $\$ 2839$ (range $-\$ 60,870$ to $\$ 1,137,054)$, with median incremental effects of 0.14 QALYs gained (range -0.26 to 3.97). The median ICERs were $\$ 53,168$ and $\$ 47,102$ for 'curative vs. curative' and 'non-curative vs. non-curative' comparisons, respectively (Fig. 2).

\subsection{Risk of Bias}

While no quantitative assessment of bias within or across studies was performed, we did note areas where potential bias could exist or limit the interpretation of the analysis. We found the types of costs included in each analysis were frequently limited. Nearly all included studies focused primarily on health sector or payer perspective costs, likely underestimating the total costs for both the interventions and comparators selected. The majority of studies also used a lifetime model time horizon. While this is a perfectly acceptable time horizon selection, longer time horizons introduce more uncertainty with the underlying model assumptions and make the model results more sensitive to discount rate selections.

\section{Discussion}

\subsection{Summary of the Findings}

To our knowledge, this systematic review is the first to assess economic models for therapies used in patients with HCC. We found a wide variety of cost-effectiveness methods used, making it difficult to compare across studies even when limiting to cost-utility analyses only. Methodological considerations such as population, disease severity, time horizon, discount rate, types of costs included, health outcomes assessed, and comparator selection can have a major influence on estimating whether HCC treatment is cost effective or not. One common theme found across HCC economic models was the use of a payer or health sector perspective that only focuses on direct costs of care (e.g., hospitalization, outpatient visits, medications). The only study that included indirect costs was in a comparison of leucovorin + fluorouracil + oxaliplatin (FOLFOX) versus sorafenib for an advanced HCC population in China [39]. In this analysis, the authors only included productivity costs due to absenteeism by multiplying days of work missed by the minimum wage for the province [39]. Additionally, two studies were inappropriately described as societal perspective analyses as they 


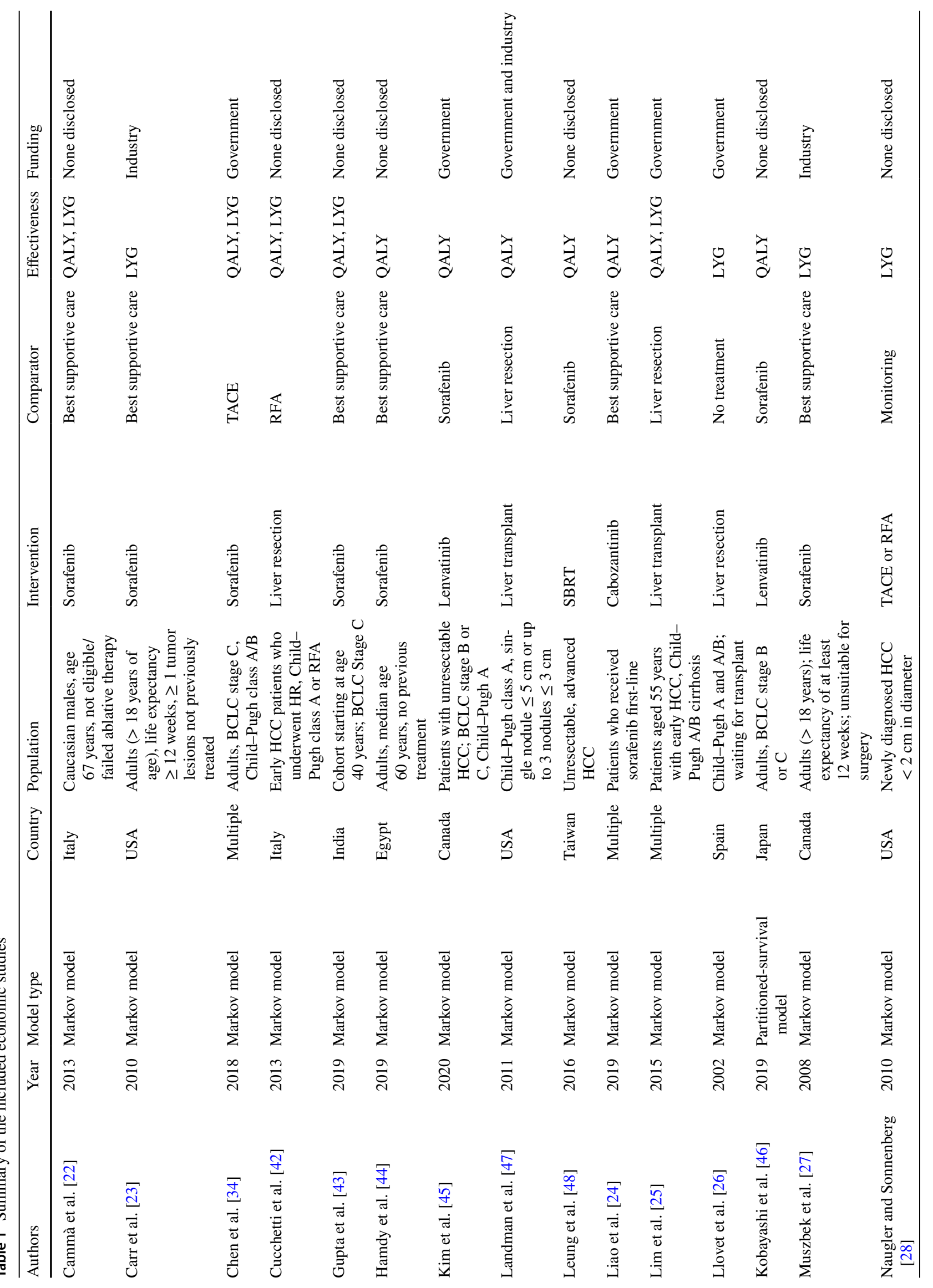




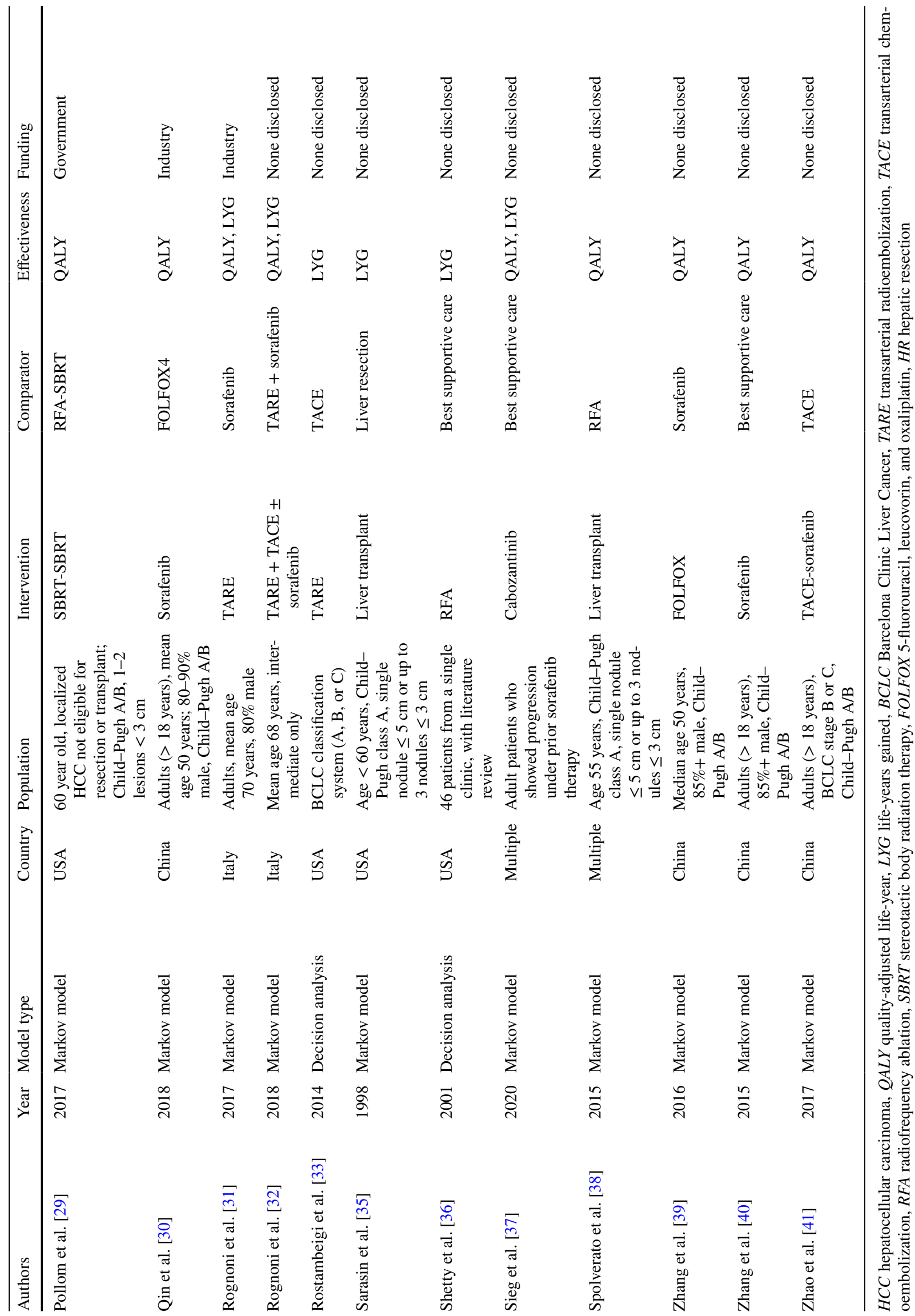


Table 2 Cost-utility analyses with costs converted to 2021 US dollars and the cost-effectiveness threshold set at \$100,000/QALY

\begin{tabular}{|c|c|c|c|c|c|c|c|c|}
\hline Authors & Country & Stage & $\begin{array}{l}\text { Comparison } \\
\text { type }\end{array}$ & $\begin{array}{l}\text { Incremen- } \\
\text { tal costs } \\
\text { reported }\end{array}$ & $\begin{array}{l}\text { Incremental } \\
\text { costs }(2021)\end{array}$ & $\begin{array}{l}\text { Incremental } \\
\text { effects }\end{array}$ & $\begin{array}{l}\text { Incremental } \\
\text { cost-effective- } \\
\text { ness ratio }\end{array}$ & $\begin{array}{l}\text { Is it cost effec- } \\
\text { tive? }\end{array}$ \\
\hline $\begin{array}{l}\text { Chen et al. } \\
\text { (2018) [34] }\end{array}$ & Multiple & Advanced & $\begin{array}{l}\text { Non-curative } \\
\text { vs. non- } \\
\text { curative }\end{array}$ & $(60,870.43)$ & $(70,565.51)$ & 0.06 & $(1,176,091.86)$ & Yes (Dominant) \\
\hline $\begin{array}{l}\text { Kim et al. } \\
\text { (2020) [45] }\end{array}$ & Canada & $\begin{array}{l}\text { Intermediate } \\
\text { and advanced }\end{array}$ & $\begin{array}{l}\text { Non-curative } \\
\text { vs. non- } \\
\text { curative }\end{array}$ & $(18,336.71)$ & $(20,037.02)$ & 0.132 & $(151,795.59)$ & Yes (Dominant) \\
\hline $\begin{array}{l}\text { Rognoni et al. } \\
\text { (2017) [31] }\end{array}$ & Italy & $\begin{array}{l}\text { Intermediate } \\
\text { and advanced }\end{array}$ & $\begin{array}{l}\text { Non-curative } \\
\text { vs. non- } \\
\text { curative }\end{array}$ & (9711.85) & $(11,596.45)$ & 0.071 & $(163,330.29)$ & Yes (Dominant) \\
\hline $\begin{array}{l}\text { Qin et al. } \\
\text { (2018) [30] }\end{array}$ & China & Advanced & $\begin{array}{l}\text { Non-curative } \\
\text { vs. non- } \\
\text { curative }\end{array}$ & 4370.00 & 4918.47 & -0.04 & $(122,961.84)$ & $\begin{array}{l}\text { No (Comparator } \\
\text { Dominant) }\end{array}$ \\
\hline $\begin{array}{l}\text { Kobayashi } \\
\text { et al. (2019) } \\
\text { [46] }\end{array}$ & Japan & $\begin{array}{l}\text { Intermediate } \\
\text { and advanced }\end{array}$ & $\begin{array}{l}\text { Non-curative } \\
\text { vs. non- } \\
\text { curative }\end{array}$ & $(5052.90)$ & $(5,687.09)$ & 0.23 & $(24,726.46)$ & Yes (Dominant) \\
\hline $\begin{array}{l}\text { Rognoni et al. } \\
\text { (2018) [32] }\end{array}$ & Italy & Intermediate & $\begin{array}{l}\text { Non-curative } \\
\text { vs. non- } \\
\text { curative }\end{array}$ & $(6933.74)$ & $(8038.11)$ & 0.448 & $(17,942.20)$ & Yes (Dominant) \\
\hline $\begin{array}{l}\text { Landman et al. } \\
\text { (2011) [47] }\end{array}$ & USA & $\begin{array}{l}\text { Very early and } \\
\text { early }\end{array}$ & $\begin{array}{l}\text { Curative vs. } \\
\text { curative }\end{array}$ & $(10,000.00)$ & $(14,685.34)$ & 2.4 & (6118.89) & Yes (Dominant) \\
\hline $\begin{array}{l}\text { Gupta et al. } \\
\text { (2019) [43] }\end{array}$ & India & Advanced & $\begin{array}{l}\text { Non-curative } \\
\text { vs. non- } \\
\text { curative }\end{array}$ & 1409.90 & 1586.86 & 0.19 & 8351.89 & Yes \\
\hline $\begin{array}{c}\text { Cucchetti et al. } \\
\text { (2013) [42] }\end{array}$ & Italy & Early & $\begin{array}{l}\text { Curative vs. } \\
\text { curative }\end{array}$ & 4216.00 & 5500.92 & 0.3 & $18,336.41$ & Yes \\
\hline $\begin{array}{r}\text { Cammà et al. } \\
\text { (2013) [22] }\end{array}$ & Italy & $\begin{array}{l}\text { Intermediate } \\
\text { and advanced }\end{array}$ & $\begin{array}{l}\text { Non-curative } \\
\text { vs. non- } \\
\text { curative }\end{array}$ & $16,481.68$ & $21,504.85$ & 0.44 & $48,874.67$ & Yes \\
\hline $\begin{array}{l}\text { Zhao et al. } \\
\text { (2017) [41] }\end{array}$ & China & $\begin{array}{l}\text { Intermediate } \\
\text { and advanced }\end{array}$ & $\begin{array}{l}\text { Non-curative } \\
\text { vs. non- } \\
\text { curative }\end{array}$ & $17,591.00$ & $21,004.57$ & 0.31 & $67,756.69$ & Yes \\
\hline $\begin{array}{l}\text { Spolverato } \\
\text { et al. (2015) } \\
\text { [38] }\end{array}$ & Multiple & Early & $\begin{array}{l}\text { Curative vs. } \\
\text { curative }\end{array}$ & $92,282.00$ & $120,407.08$ & 1 & $120,407.08$ & No \\
\hline $\begin{array}{l}\text { Zhang et al. } \\
\text { (2015) [40] }\end{array}$ & China & Advanced & $\begin{array}{l}\text { Non-curative } \\
\text { vs. non- } \\
\text { curative }\end{array}$ & $18,252.00$ & $21,793.84$ & 0.18 & $121,076.90$ & No \\
\hline $\begin{array}{l}\text { Lim et al. } \\
\quad(2015) \text { [25] }\end{array}$ & Multiple & Early & $\begin{array}{l}\text { Curative vs. } \\
\text { curative }\end{array}$ & $163,006.00$ & $212,685.86$ & 1.4 & $151,918.47$ & No \\
\hline $\begin{array}{l}\text { Leung et al. } \\
\text { (2016) [48] }\end{array}$ & Taiwan & Advanced & $\begin{array}{l}\text { Non-curative } \\
\text { vs. non- } \\
\text { curative }\end{array}$ & $(30,757.33)$ & $(36,725.86)$ & -0.26 & $141,253.31$ & No \\
\hline $\begin{array}{l}\text { Hamdy Elsisi } \\
\text { et al. (2019) } \\
\text { [44] }\end{array}$ & Egypt & Advanced & $\begin{array}{l}\text { Non-curative } \\
\text { vs. non- } \\
\text { curative }\end{array}$ & $1,137,054.00$ & $1,279,764.29$ & 3.97 & $322,358.76$ & No \\
\hline $\begin{array}{l}\text { Pollom et al. } \\
\text { (2017) [29] }\end{array}$ & USA & Early & $\begin{array}{l}\text { Non-curative } \\
\text { vs. non- } \\
\text { curative }\end{array}$ & 4269.00 & 5097.41 & 0.007 & $728,201.32$ & No \\
\hline $\begin{array}{l}\text { Liao et al. } \\
\text { (2019) [24] }\end{array}$ & Multiple & Advanced & $\begin{array}{l}\text { Non-curative } \\
\text { vs. non- } \\
\text { curative }\end{array}$ & $108,521.00$ & $122,141.34$ & 0.13 & $939,548.78$ & No \\
\hline $\begin{array}{l}\text { Zhang et al. } \\
\text { (2016) [39] }\end{array}$ & China & Advanced & $\begin{array}{l}\text { Non-curative } \\
\text { vs. non- } \\
\text { curative }\end{array}$ & $(11,872.00)$ & $(14,175.79)$ & -0.0127 & $1,116,203.85$ & No \\
\hline
\end{tabular}


Table 2 (continued)

\begin{tabular}{|c|c|c|c|c|c|c|c|c|}
\hline Authors & Country & Stage & $\begin{array}{l}\text { Comparison } \\
\text { type }\end{array}$ & $\begin{array}{l}\text { Incremen- } \\
\text { tal costs } \\
\text { reported }\end{array}$ & $\begin{array}{l}\text { Incremental } \\
\text { costs }(2021)\end{array}$ & $\begin{array}{l}\text { Incremental } \\
\text { effects }\end{array}$ & $\begin{array}{l}\text { Incremental } \\
\text { cost-effective- } \\
\text { ness ratio }\end{array}$ & $\begin{array}{l}\text { Is it cost effec- } \\
\text { tive? }\end{array}$ \\
\hline $\begin{array}{l}\text { Sieg et al. } \\
\text { (2020) [37] }\end{array}$ & Multiple & Advanced & $\begin{array}{l}\text { Non-curative } \\
\text { vs. non- } \\
\text { curative }\end{array}$ & $172,866.00$ & $183,393.54$ & 0.15 & $1,222,623.60$ & No \\
\hline
\end{tabular}

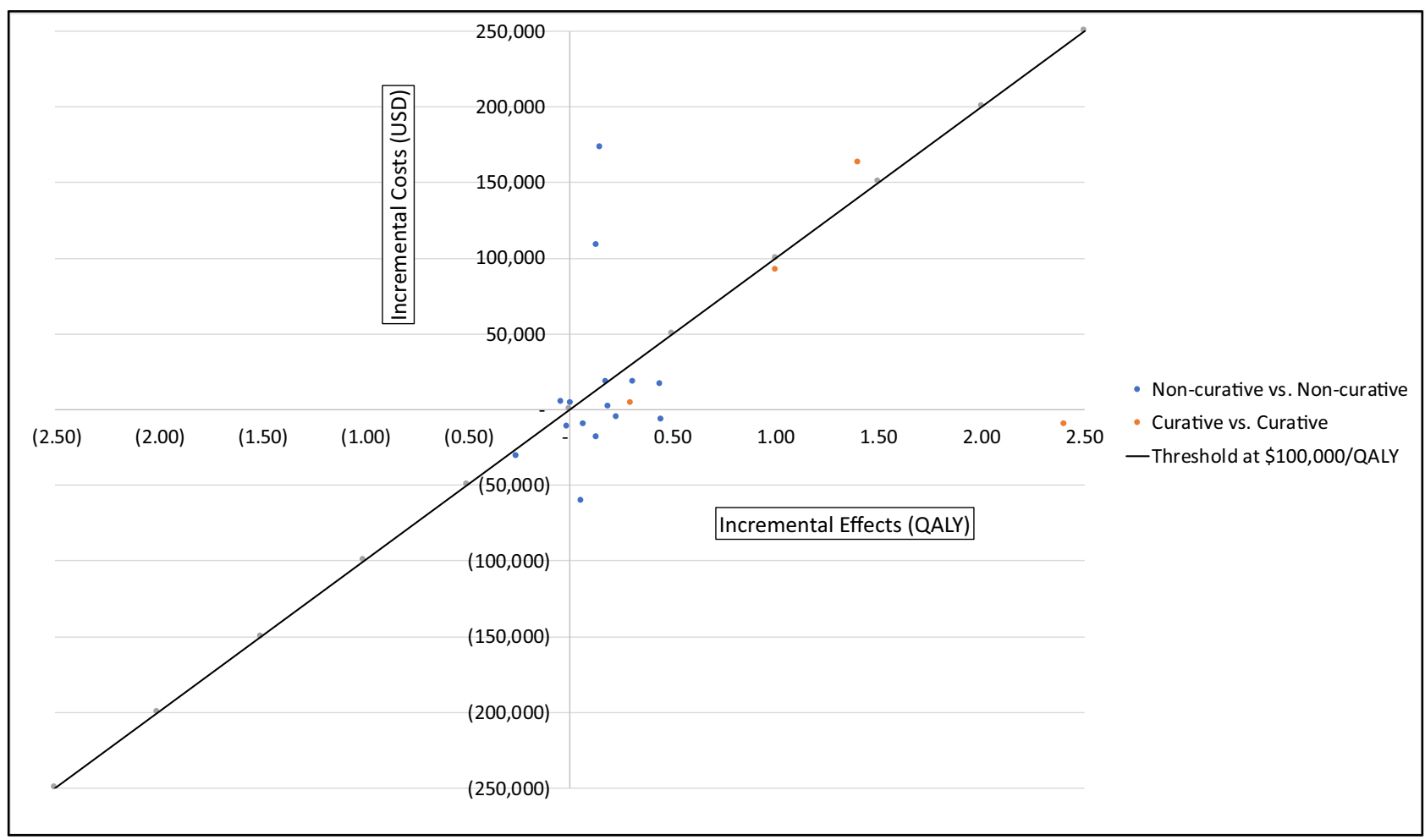

Fig. 2 Incremental cost-effectiveness ratios for 'non-curative vs. non-curative' and 'curative vs. curative' comparisons with a cost-effectiveness threshold at \$100,000/QALY. QALY quality-adjusted life-year, USD US dollars

failed to include any indirect costs or costs outside the more narrow payer perspective [43, 47].

In terms of cost effectiveness, ICERs reported varied widely from - $\$ 1,176,091$ [34] to $\$ 1,152,440$ [37], demonstrating how difficult it is to compare ICERs across studies without limiting the comparison to studies with nearly identical evaluation methods. For example, Chen et al. aimed to compare dose-adjusted sorafenib versus TACE in a limited advanced-stage HCC population using lifetime costs, resulting in the lowest ICER reported [34]. In contrast, Sieg et al. compared cabozantinib versus best supportive care as a 'second-line therapy' in a similar advanced-stage HCC, resulting in the highest ICER reported [37]. Selecting a very low-cost 'supportive care' treatment as a comparator seems to be a driving factor for such a large ICER in treatment only, adding an estimated 9.4 weeks of life $(0.18$ LYG). This demonstrates how economic evaluations can vary widely within a similar population based on the clinical scenario and treatment comparisons.

Future CEAs for HCC treatments should consider the use of an impact inventory that explicitly shows the direct and indirect costs included and which perspective includes each cost type [9]. Health economists may also want to consider engaging HCC patients and caregivers in the CEA process to validate that the model structure chosen reflects the patient experience, identify appropriate comparators and outcomes, and identify which costs are most important to patients [49-51]. While evidence suggests HCC and other types of cancer cause significant burdens on family and caregivers, no studies in our analysis have considered the potential spillover effects of the disease on the supportive network around the patient $[3,52]$.

When considering the potential risk of bias within and across studies included, the most glaring source of bias 
comes from the limited types of costs included in each analysis. This health sector or payer perspective focus for HCC evaluations likely underestimates the total costs for both the interventions and comparators selected. Since this underestimation is applied to both intervention and comparator, the final direction and size of the introduced bias when assessing incremental costs or an ICER may be difficult to predict. Most studies selected a lifetime time horizon for the primary analysis, with 10- and 5-year horizons commonly selected for studies shorter than lifetime. This modeling decision may be appropriate to the individual research question, however longer time horizons create greater uncertainty beyond the bounds of the underlying data inputs and put greater importance on the discount rate selection.

\subsection{Limitations}

Since our systematic review focused on economic evaluations, the heterogeneity of methods made it inappropriate to use traditional meta-analysis methods to pool results. We described costs and cost-effectiveness results, categorizing and comparing where appropriate and providing qualitative assessment of different components. We did attempt to draw comparisons on reported costs by exchanging the currency used to US\$ and then inflating to 2021 US\$ using a flat $3 \%$ discount rate, similar to discount approaches applied by many health technology assessment bodies [53]. However, we did not apply different inflation rates across studies, which may better reflect price changes for non-tradable resources where the study was conducted but can potentially overestimate the adjusted cost [54]. Additionally, the generalizability of any pooled results may be limited when considering the differences in health system structures across countries or when considering the within-study differences described in this article. While we reported descriptive statistics for costs and ICERs reported, the usefulness of a mean or median statistic may be less than the range of reported values, demonstrating how important methodological considerations are when interpreting economic evaluations. Finally, for treatment categorization purposes, we did not differentiate based on dosage or the variability in transplantation or resection procedures. In our analysis, these groupings were broadly defined. Studies may also include wide variations in 'standard of care' or 'best supportive care' that were not assessed in this review. This review may help guide future researchers interested in estimating the value or cost effectiveness of different treatment options in HCC patients and encourage the use of existing recommendations and best practices in the conduct and reporting of CEAs [9].

\section{Conclusions}

Economic evaluations for the treatment of HCC are conducted using a variety of methods and modeling decisions that make it difficult to compare across studies. For costutility analyses specifically, the majority of HCC treatments were found to be cost effective at a \$100,000/QALY willingness-to-pay threshold, but with a wide range and with very few studies considering indirect costs. Future value assessment for HCC treatments should incorporate multiple perspectives and engage patients and caregivers to ensure the evaluation reflects the true patient experience.

Supplementary Information The online version contains supplementary material available at https://doi.org/10.1007/s41669-021-00298-z.

Acknowledgements None.

\section{Declarations}

Funding No financial support received for this work.

Author contributions Study concept and design: All authors. Abstract Review and Data Extraction: SY, AA, HK, BO. Drafting of the manuscript: SY, TJM. Critical reviews: All authors. Statistical analysis: TJM. Interpretation of data: All authors. Approval of the Final Version: All authors.

Conflicts of interest TJM reports receiving consultant fees from PhRMA, NHC, and Johns Hopkins University, all unrelated to this research. Sydney Yuen, Adaeze Q. Amaefule, Hannah H. Kim, BreannaVerissa Owoo1, and Emily F. Gorman report no conflicts of interest.

Data availability statement All data generated or analyzed during this study are included in this published article (and its supplementary information files).

Open Access This article is licensed under a Creative Commons Attribution-NonCommercial 4.0 International License, which permits any non-commercial use, sharing, adaptation, distribution and reproduction in any medium or format, as long as you give appropriate credit to the original author(s) and the source, provide a link to the Creative Commons licence, and indicate if changes were made. The images or other third party material in this article are included in the article's Creative Commons licence, unless indicated otherwise in a credit line to the material. If material is not included in the article's Creative Commons licence and your intended use is not permitted by statutory regulation or exceeds the permitted use, you will need to obtain permission directly from the copyright holder. To view a copy of this licence, visit http://creativecommons.org/licenses/by-nc/4.0/.

\section{References}

1. Yang JD, Hainaut P, Gores GJ, Amadou A, Plymoth A, Roberts LR. A global view of hepatocellular carcinoma: trends, risk, prevention and management. Nat Rev Gastroenterol Hepatol. 2019;16:589-604. 
2. Kulik L, El-Serag HB. Epidemiology and management of hepatocellular carcinoma. Gastroenterology. 2019;156:477-491.e1.

3. Aly A, Ronnebaum S, Patel D, Doleh Y, Benavente F. Epidemiologic, humanistic and economic burden of hepatocellular carcinoma in the USA: a systematic literature review. Hepatic Oncol. 2020;7:HEP27.

4. Gill J, Baiceanu A, Clark PJ, Langford A, Latiff J, Yang PM, et al. Insights into the hepatocellular carcinoma patient journey: results of the first global quality of life survey. Futur Oncol. 2018;14:1701-10.

5. White LA, Menzin J, Korn JR, Friedman M, Lang K, Ray S. Medical care costs and survival associated with hepatocellular carcinoma among the elderly. Clin Gastroenterol Hepatol. 2012;10:547-54.

6. Beste LA, Leipertz SL, Green PK, Dominitz JA, Ross D, Ioannou GN. Trends in burden of cirrhosis and hepatocellular carcinoma by underlying liver disease in US veterans, 2001-2013. Gastroenterology. 2015;149:1471-1482.e5.

7. Neumann PJ, Sanders GD, Russell LB, Siegel JE, Ganiats TG, editors. Cost-effectiveness in health and medicine. 2nd ed. New York: Oxford University Press; 2017.

8. Siegel JE, Weinstein MC, Russell LB, Gold MR. Recommendations for reporting cost-effectiveness analyses. JAMA. 1996;276:1339-41.

9. Sanders GD, Neumann PJ, Basu A, Brock DW, Feeny D, Krahn $\mathrm{M}$, et al. Recommendations for conduct, methodological practices, and reporting of cost-effectiveness analyses. JAMA. 2016;316:1093-103.

10. Kim DD, Silver MC, Kunst N, Cohen JT, Ollendorf DA, Neumann PJ. Perspective and costing in cost-effectiveness analysis, 1974-2018. Pharmacoeconomics. 2020;38:1135-45.

11. Weinstein MC, Siegel JE, Gold MR, Kamlet MS, Russell LB. Recommendations of the panel on cost-effectiveness in health and medicine. JAMA. 1996;276:1253-8.

12. Moher D, Liberati A, Tetzlaff J, Altman DG, The PRISMA Group. Preferred reporting items for systematic reviews and meta-analyses: the PRISMA Statement. PLoS Med. 2009;6:e1000097.

13. Husereau D, Drummond M, Petrou S, Carswell C, Moher D, Greenberg D. Consolidated Health Economic Evaluation Reporting Standards (CHEERS) — explanation and elaboration: a report of the ISPOR Health Economic Evaluations Publication Guidelines Task Force. Value Health. 2013;16:231-50.

14. Covidence systematic review software. Melbourne, VIC: Veritas Health Innovation. 2020. www.covidence.org.

15. Marrero JA, Kulik LM, Sirlin CB, Zhu AX, Finn RS, Abecassis $\mathrm{MM}$, et al. Diagnosis, staging, and management of hepatocellular carcinoma: 2018 practice guidance by the american association for the study of liver diseases. Hepatology. 2018;68:723-50.

16. OANDA Corporation. Currency Converter. 2019. https://www1. oanda.com/currency/converter/. Accessed 30 Jun 2019.

17. Vanness DJ, Lomas J, Ahn H. A health opportunity cost threshold for cost-effectiveness analysis in the United States. Ann Intern Med. 2021;174(1):25-32.

18. Heimbach JK, Kulik LM, Finn RS, Sirlin CB, Abecassis MM, Roberts LR, et al. AASLD guidelines for the treatment of hepatocellular carcinoma. Hepatology. 2018;67:358-80.

19. Rich NE, Yopp AC, Singal AG. Medical management of hepatocellular carcinoma. J Oncol Pract. 2017;13:356-64.

20. Basu A. Estimating costs and valuations of non-health benefits in cost-effectiveness analysis. In: Neumann PJ, Sanders GD, Russell LB, Siegel JE, Ganiats TG, editors. Cost-effectiveness in health and medicine. 2nd ed. New York: Oxford University Press; 2017. p. 201-35.

21. Black WC, The CE. Plane: a graphic representation of cost-effectiveness. Med Decis Making. 1990;10:212-4.
22. Cammà C, Cabibbo G, Petta $S$, Enea M, Iavarone M, Grieco A, et al. Cost-effectiveness of sorafenib treatment in field practice for patients with hepatocellular carcinoma. Hepatology. 2013;57:1046-54.

23. Carr BI, Carroll S, Muszbek N, Gondek K. Economic evaluation of sorafenib in unresectable hepatocellular carcinoma. J Gastroenterol Hepatol. 2010;25:1739-46.

24. Liao W, Huang J, Hutton D, Zhu G, Wu Q, Wen F, et al. Costeffectiveness analysis of cabozantinib as second-line therapy in advanced hepatocellular carcinoma. Liver Int. 2019;39:2408-16.

25. Lim KC, Wang VW, Siddiqui FJ, Shi L, Chan ESY, Oh HC, et al. Cost-effectiveness analysis of liver resection versus transplantation for early hepatocellular carcinoma within the Milan criteria. Hepatology. 2015;61:227-37.

26. Llovet JM, Mas X, Aponte JJ, Fuster J, Navasa M, Christensen E, et al. Cost effectiveness of adjuvant therapy for hepatocellular carcinoma during the waiting list for liver transplantation. Gut. 2002;50:123-8.

27. Muszbek N, Shah S, Carroll S, McDonald H, Dale P, Maroun $\mathrm{J}$, et al. Economic evaluation of sorafenib in the treatment of hepatocellular carcinoma in Canada. Curr Med Res Opin. 2008;24:3559-69.

28. Naugler WE, Sonnenberg A. Survival and cost-effectiveness analysis of competing strategies in the management of small hepatocellular carcinoma. Liver Transplant. 2010;16:1186-94.

29. Pollom EL, Lee K, Durkee BY, Grade M, Mokhtari DA, Wahl DR, et al. Cost-effectiveness of stereotactic body radiation therapy versus radiofrequency ablation for hepatocellular carcinoma: a Markov modeling study. Radiology. 2017;283:460-8.

30. Qin S, Kruger E, Tan SC, Cheng S, Wang N, Liang J. Cost-effectiveness analysis of FOLFOX4 and sorafenib for the treatment of advanced hepatocellular carcinoma in China. Cost Eff Resour Alloc. 2018;16:1-9.

31. Rognoni C, Ciani O, Sommariva S, Tarricone R. Real-world data for the evaluation of transarterial radioembolization versus sorafenib in hepatocellular carcinoma: a cost-effectiveness analysis. Value Health. 2017;20:336-44.

32. Rognoni C, Ciani O, Sommariva S, Tarricone R. Cost-effectiveness analysis of treatments involving radioembolization in intermediate-stage hepatocellular carcinoma. J Comp Eff Res. 2018;7:209-21.

33. Rostambeigi N, Dekarske AS, Austin EE, Golzarian J, Cressman EN. Cost effectiveness of radioembolization compared with conventional transarterial chemoembolization for treatment of hepatocellular carcinoma. J Vasc Interv Radiol. 2014;25:1075-84.

34. Chen S, Peng Z, Wei M, Liu W, Dai Z, Wang H, et al. Sorafenib versus Transarterial chemoembolization for advanced-stage hepatocellular carcinoma: a cost-effectiveness analysis. BMC Cancer. 2018;18:1-12.

35. Sarasin FP, Giostra E, Mentha G, Hadengue A. Partial hepatectomy or orthotopic liver transplantation for the treatment of resectable hepatocellular carcinoma? A cost-effectiveness perspective. Hepatology. 1998;28:436-42.

36. Shetty SK, Rosen MP, Raptopoulos V, Goldberg SN. Cost-effectiveness of percutaneous radiofrequency ablation for malignant hepatic neoplasms. J Vasc Interv Radiol. 2001;12:823-33.

37. Sieg M, Hartmann M, Settmacher U, Arefian H. Comparative costeffectiveness of cabozantinib as second-line therapy for patients with advanced hepatocellular carcinoma in Germany and the United States. BMC Gastroenterol. 2020;20:1-12.

38. Spolverato G, Vitale A, Ejaz A, Kim Y, Maithel SK, Cosgrove DP, et al. The relative net health benefit of liver resection, ablation, and transplantation for early hepatocellular carcinoma. World J Surg. 2015;39:1474-84.

39. Zhang P, Wen F, Li Q. FOLFOX4 or sorafenib as the firstline treatments for advanced hepatocellular carcinoma: a 
cost-effectiveness analysis. Dig Liver Dis Editrice Gastroenterol Ital. 2016;48:1492-7.

40. Zhang P, Yang Y, Wen F, He X, Tang R, Du Z, et al. Cost-effectiveness of sorafenib as a first-line treatment for advanced hepatocellular carcinoma. Eur J Gastroenterol Hepatol. 2015;27:853-9.

41. Zhao RC, Zhou J, Wei YG, Liu F, Chen KF, Li Q, et al. Cost-effectiveness analysis of transcatheter arterial chemoembolization with or without sorafenib for the treatment of unresectable hepatocellular carcinoma. Hepatobiliary Pancreat Dis Int. 2017;16:493-8.

42. Cucchetti A, Piscaglia F, Cescon M, Colecchia A, Ercolani G, Bolondi L, et al. Cost-effectiveness of hepatic resection versus percutaneous radiofrequency ablation for early hepatocellular carcinoma. J Hepatol. 2013;59:300-7.

43. Gupta N, Verma RK, Prinja S, Dhiman RK. Cost-effectiveness of sorafenib for treatment of advanced hepatocellular carcinoma in India. J Clin Exp Hepatol. 2019;9:468-75.

44. Hamdy Elsisi G, Nada Y, Rashad N, Carapinha J. Cost-effectiveness of sorafenib versus best supportive care in advanced hepatocellular carcinoma in Egypt. J Med Econ. 2019;22:163-8.

45. Kim JJ, McFarlane T, Tully S, Wong WWL. Lenvatinib versus sorafenib as first-line treatment of unresectable hepatocellular carcinoma: a cost-utility analysis. Oncologist. 2020;25:512-9.

46. Kobayashi M, Kudo M, Izumi N, Kaneko S, Azuma M, Copher $\mathrm{R}$, et al. Cost-effectiveness analysis of lenvatinib treatment for patients with unresectable hepatocellular carcinoma (uHCC) compared with sorafenib in Japan. J Gastroenterol. 2019;54:558-70.
47. Landman MP, Feurer ID, Pinson CW, Moore DE. Which is more cost-effective under the MELD system: Primary liver transplantation, or salvage transplantation after hepatic resection or after loco-regional therapy for hepatocellular carcinoma within Milan criteria? HPB. 2011;13:783-91.

48. Leung HWC, Liu CF, Chan ALF. Cost-effectiveness of sorafenib versus SBRT for unresectable advanced hepatocellular carcinoma. Radiat Oncol. 2016;11:1-9.

49. Mattingly TJ II, Perfetto EM, Johnson SL. Engaging hepatitis C infected patients in cost-effectiveness analyses: a literature review. Hepatology. 2018;67(2):774-81.

50. Mattingly TJ II, Slejko JF, Perfetto EM, Kottilil S, Mullins CD. What matters most for treatment decisions in hepatitis C: effectiveness, costs, and altruism. Patient. 2019;12:631-8.

51. Slejko JF, Mattingly TJ II, Mullins CD, Perfetto EM, DosReis S. Future of patients in healthcare evaluation: the patient-informed reference case. Value Health. 2019;22:545-8.

52. Yu W, Chen J, Sun S, Liu P, Ouyang L, Hu J. The reciprocal associations between caregiver burden, and mental health in primary caregivers of cancer patients: a longitudinal study. Psychooncology. 2021;30(6):892-900.

53. Attema AE, Brouwer WBF, Claxton K. Discounting in economic evaluations. Pharmacoeconomics. 2018;36:745-58.

54. Turner HC, Lauer JA, Tran BX, Teerawattananon Y, Jit M. Adjusting for inflation and currency changes within health economic studies. Value Health. 2019;22:1026-32. 